\title{
59. THE THEORY OF SPIRAL STRUCTURE OF GALAXIES
}

\author{
L. S. MAROCHNIK \\ Astrophysical Institute of the Academy of Sciences of the Tadjik S.S.R., \\ Dushanbe, U.S.S.R.
}

\begin{abstract}
A Landau-type instability mechanism for generating spiral waves is suggested.
Two populations of stars, Populations I and II, are considered, the second one with mean rotational velocity zero. Then a dispersion relation is derived which is reduced to the Lin-Shu dispersion relation in the case of vanishing Population II. The amplification of the wave is of the same type as the twostream instability. It occurs if the angular velocity of the spiral pattern $\Omega_{\mathrm{s}}$ is smaller than the angular velocity of the Population I stars. A value of $\Omega_{\mathrm{s}}=22-25 \mathrm{~km} \mathrm{~s}^{-1} \mathrm{kpc}^{-1}$ was found, as well as the growth parameter. Spiral arms are formed in $10^{8}-10^{9} \mathrm{yr}$, while trailing and leading waves grow at the same rate.

A quasi-linear theory is developed to account for the limited growth of the spiral waves.

Detailed accounts of the theory and of its implications are contained in recent publications (Marochnik, 1969; Marochnik and Suchkov, 1969a; 1969b; Marochnik and Ptitzina, 1969; Marochnik et al., 1969).
\end{abstract}

\section{References}

Marochnik, L. S.: 1969, Astrofiz. 15, 487.

Marochnik, L. S. and Suchkov, A. A.: 1969a, Astron. Zh. 46, 319, 524.

Marochnik, L. S. and Suchkov, A. A.: 1969b, Astrophys. Space Sci. 4, 317.

Marochnik, L. S. and Ptitzina, N. G.: 1969, Astron. Zh. 46, 762.

Marochnik, L. S., Pomagaev, S. G., Sagdeev, R. Z., and Suchkov, A. A.: 1969, Dokl. Akad. Nauk S.S.S.R., in press. 